\title{
Pregnancy and its outcome among hospital personnel according to occupation and working conditions
}

\author{
$M$ J SAUREL-CUBIZOLLES, ${ }^{1}$ M KAMINSKI, ${ }^{1} \mathrm{~J}^{\text {LLADO-ARKHIPOFF, }}{ }^{1}$ C DU \\ MAZAUBRUN,${ }^{1} \mathrm{M}$ ESTRYN-BEHAR, ${ }^{2}$ C BERTHIER, ${ }^{2}$ M MOUCHET, ${ }^{2}$ AND \\ C KELFA ${ }^{2}$ \\ From Unité de Recherches Epidémiologiques sur la Mère et l'Enfant, ${ }^{1}$ INSERM Unité 149, Villejuif, France; \\ and Services de Médecine de Travail ${ }^{2}$ des Hôpitaux Saint-Antoine (Paris), Kremlin-Bicêtre, Tenon (Paris), \\ Saint-Vincent de Paul (Paris) France
}

SUMMARY Relationships between occupation, working conditions, and the development and outcome of pregnancy were analysed on a sample of women employed in hospital during their pregnancy. Ancillary staff members experienced more uterine contractions during pregnancy, more preterm deliveries, and more low birthweight infants than those performing other duties; this remained true after adjusting for social characteristics. The rate of preterm delivery was significantly higher in the presence of at least two of the following arduous working conditions: stand-up work, carrying heavy loads (exclusive of patients), and heavy cleaning tasks; this was so, whatever the occupation.

Increasing interest is being shown in the possible risks of occupational activity during pregnancy. ${ }^{1-3}$ Some recent studies have shown that paid work was not in itself a risk factor for the outcome of a pregnancy; on the contrary, working women had, on the whole, a lower rate of preterm delivery than nonworking women. ${ }^{4-7}$ However, these same studies ${ }^{45}$ revealed the risks associated with certain strenuous working conditions or particular occupations. A study carried out in Paris from 1974 to 1976 showed that pregnant women working in hospitals had a higher preterm delivery rate than the overall population of women in the Paris region. ${ }^{8}$ There is a special need to study working conditions in hospital because of their specificity and because of the large number of women involved: in France, in 1981, 700000 persons, excluding medical doctors, were working in public and private hospitals, ${ }^{9}$ of whom 80 to $95 \%$, according to category of occupation, were women..$^{10}$

This paper analyses the development and outcome of pregnancies among a group of women working in hospitals, according to occupation and working conditions.

\section{Population and method}

The study was conducted in seven of the main public hospitals in the Paris region between 1979 and 1981 . It included all women working in these hospitals, except doctors, during their pregnancies. The data were collected by the hospital staff occupational health practitioners by interviewing women during their routine medical visit before resuming work at the end of postnatal leave. The data covered their occupation, working conditions, social characteristics, medical history, pregnancy, delivery, and condition of the infant at birth. Of the 720 women in the study sample, 53 were not interviewed, mainly because of the occupational health practitioner's lack of time ( 33 cases), or because they had worked less than a trimester during their pregnancy (15 cases). Women who had been interviewed even though they had worked less than 13 weeks during the pregnancy, or for whom the duration of work was unknown, and the women who had resumed their work later than 36 weeks after delivery were systematically excluded from the sample; the study finally included 621 women.

The study compared the development and outcome of the pregnancies of these women according to their occupation and working conditions. Four indicators were considered: (1) uterine contractions occurring between the fourth and seventh months of pregnancy; (2) hypertension (blood pressure over $130 / 80 \mathrm{~mm} \mathrm{Hg}$ ); (3) preterm delivery, occurring before 8 months and 0 weeks since the presumed date of conception (which corresponds to 36.5 completed 
weeks since the first day of the last menstrual period); (4) birth weight less than $2500 \mathrm{~g}$.

Four categories of occupations were considered: (1) nurses, including head nurses and midwives; (2) auxiliaries, who share in providing care under the direction of a nurse; (3) ancillary staff, who carry out housekeeping duties in the wards or in the hospital's general services; (4) other occupations.

The first three groups correspond to three occupations clearly defined, occupying very specific positions in the hospital hierarchy. The "other occupations" include numerous professions of a varied nature, each being insufficiently represented to permit detailed analysis: administrative staff ( 58 cases), laboratory assistants (38 cases), x-ray examination technicians (17 cases), cleaners paid by the hour (13 cases), physiotherapists (5 cases), student nurses (8 cases), and other occupations such as social workers or nursery auxiliaries ( 37 cases), etc.

Data from ergonomic studies of hospital work, ${ }^{11}{ }^{12}$ as well as a preliminary analysis of pregnancy outcome according to working conditions, ${ }^{13}$ led to the selection of three of these: heavy cleaning tasks (including floor or window cleaning), carrying heavy loads (other than lifting patients), and lengthy periods of standing. A cumulative indicator was constructed by calculating for each woman the number of these working conditions to which she had been exposed.

Taking into account the relationships often evidenced between the outcome of pregnancy and social and demographic characteristics, ${ }^{14} 15$ adjustments were made for age, parity, and socioprofessional level of the spouse. Origin was also considered, because of the large proportion of women from the French West Indies working in the Paris public hospitals and of their high preterm birth rate in France. ${ }^{16}$

Comparisons between groups were made using Pearson's $\chi^{2}$ test or, where numbers were small, Fisher's test; in case of adjustment, Cochran's test and the analysis of variance were used.

\section{Results}

The most widely represented occupation was that of nurse: $37 \%$ of the total; there followed the ancillary staff, $18 \%$, and the auxiliaries $16 \% ; 29 \%$ of the women worked in one of the other occupations.

Forty-nine percent of the women in the sample had contractions between the fourth and seventh month of pregnancy; $14 \%$ had high blood pressure; $8 \%$ experienced a preterm delivery; and $5 \%$ gave birth to an infant weighing less than $2500 \mathrm{~g}$. The percentage of women having had contractions during pregnancy, the percentage of preterm deliveries and of infants having a birthweight less than $2500 \mathrm{~g}$ varied significantly according to occupation (table 1). They were higher for ancillary staff than for other occupations, particularly with respect to the outcome of pregnancy, since, among these women, the percentage of preterm infants and of those weighing less than $2500 \mathrm{~g}$ were double those in the overall sample. It is in the group of occupations other than nurses, auxiliaries, and ancillary staff that pathology was least frequent. The percentage of hypertension during pregnancy did not differ significantly by occupation.

Table 1 Development and outcome of pregnancy according to occupation

\begin{tabular}{|c|c|c|c|c|c|c|c|c|}
\hline \multirow[b]{2}{*}{ Occupation } & \multicolumn{2}{|c|}{$\begin{array}{l}\text { Uterine } \\
\text { contractions }\end{array}$} & \multicolumn{2}{|c|}{ Hypertension } & \multicolumn{2}{|c|}{$\begin{array}{l}\text { Preterm } \\
\text { delivery }\end{array}$} & \multicolumn{2}{|c|}{$\begin{array}{l}\text { Birthweight } \\
<2500 \mathrm{~g}\end{array}$} \\
\hline & No & $\%$ & No & $\%$ & No & $\%$ & No & $\%$ \\
\hline All women & 621 & 49 & 621 & 14 & 610 & 8 & 617 & 6 \\
\hline Nurses & 227 & 54 & 227 & 15 & 224 & 8 & 227 & 6 \\
\hline Auxiliaries & 100 & 46 & 100 & 14 & 97 & 7 & 97 & 2 \\
\hline $\begin{array}{l}\text { Ancillary } \\
\text { staff }\end{array}$ & 113 & 58 & 113 & 17 & 111 & 16 & 112 & 11 \\
\hline Other & & & & & & & & \\
\hline occupations & 180 & $\begin{array}{l}40 \\
\neq \neq\end{array}$ & 180 & $\begin{array}{l}12 \\
\text { ns }\end{array}$ & 177 & $\begin{array}{c}5 \\
\neq \neq\end{array}$ & 180 & $\stackrel{3}{\not}$ \\
\hline
\end{tabular}

No = total number of mothers in group

$\%=$ per cent with the particular characteristic

ns $\mathrm{p}>0.05, \neq \mathrm{p}<0.05 \neq \neq \quad \mathrm{p}<0.01$

Hospital personnel belonged to different sociat on groups, according to their occupation. The ancillary staff constituted the most underprivileged social group: $59 \%$ of them were married to manual workers compared to $54 \%$ of the auxiliaries, $27 \%$ of the nurses, and $24 \%$ among the other occupations $(p<0.001)$. The ancillary staff and auxiliaries had a higher parity: respectively 19 and $29 \%$ among them already had two children or more at the time of the pregnancy studied, compared to $8 \%$ among the nurses and $6 \%$ among those from the other occupations $(p<0.001)$. The ancillary staff constituted a younger group: $52 \%$ were under 25 years of age, while only $16 \%$ of the auxiliaries were in this age category, $22 \%$ of the nurses, and $26 \%$ of those in the other occupations $(p<0.001)$. But these social and demographic characteristics did not wholly explain the differences in the outcome of pregnancy among the occupations. After adjusting for the socioprofessional category of the spouse, for parity, and for age, the percentage of contractions, preterm births, and birthweight less than $2500 \mathrm{~g}$ remained significantly different according to occupation.

Twenty-seven percent of the sample were women born in French overseas departments, mainly the 
West Indies; $3 \%$ were born in foreign countries. The women born in overseas France had a higher percentage of preterm deliveries than those born in continental France: 14\% against 6\% (table 2). The frequency of low birthweight was not linked to the place of birth. Women born in overseas France were more often ancillary staff members or auxiliaries than women born in continental France: the respective figures were 33 and $35 \%$, against 13 and $9 \%$ $(\mathrm{p}<0.001)$. After adjusting for place of birth, the relationship between occupation and preterm delivery was no longer significant, even though preterm births still occurred more frequently among ancillary staff members (table 2).

The development and outcome of the pregnancy were related to the cumulative indicator of strenuous working conditions. The preterm delivery rate varied from $6 \%$ and $5 \%$ when, respectively, none or only one of these working conditions existed, to $18 \%$ when two and $30 \%$ when all three were accumulated $(\mathrm{p}<0.001)$. In the following analysis, women exposed to at least two of these strenuous working conditions were compared to those exposed to none or only one of them (table 3 ). In the overall sample, $19 \%$ of the women combined two or the three working conditions, but this proportion varied from $10 \%$ in the group "other occupations" to $43 \%$ among the ancillary staff; it was $12 \%$ among the nurses and $26 \%$ among the auxiliaries $(p<0 \cdot 001)$. After adjusting for occupation, the relationship between the cumulative indicator of working conditions and pregnancy pathologies remained significant, except for birthweight, for which the trend was the same. On the other hand, after adjusting for the indicator of working conditions, there was no longer any significant difference in preterm delivery or low birthweight rates according to occupation.
For the women born in overseas France, as for the natives of continental France, preterm delivery was significantly more frequent among those who accumulated two, or all three, working conditions described above, than for those who were exposed to one, or none, of these conditions: $31 \%$, compared to $7 \%$, among those born in overseas France ( $p<0.001)$, and $14 \%$, compared to $5 \%$, among women born in continental France $(p<0.05)$. The trends were the same for birthweight less than $2500 \mathrm{~g}$ : $8 \%$, compared to $4 \%$, among the women from overseas France and 9\%, compared to 5\%, among those born in continental France.

The accumulation of these working conditions was also associated with a higher frequency of hospitalisation during pregnancy and a longer duration of sick leave, including the two supplementary weeks of antenatal leave for pathological pregnancies, and this remained true even after adjusting for occupation (table 4).

Other working conditions, such as length of working hours and time of travelling to place of work, have been analysed: none was linked with the outcome of the pregnancy.

\section{Discussion}

By concentrating on an occupational group that is relatively homogeneous compared to the total active population, the study shows the influence of strenuous working conditions on pregnancy and its outcome.

The aim of this survey was to study the effects of working conditions involving heavy physical effort mainly on birthweight and preterm delivery, and not to look at specific teratological risks which some hospital jobs might involve. The frequency of adverse

Table 2 Pregnancy outcome according to occupation and women's place of birth in Continental France or the French West Indies (excluding women born elsewhere)

\begin{tabular}{|c|c|c|c|c|c|c|c|c|c|c|}
\hline \multirow[b]{3}{*}{ Occupation } & \multicolumn{5}{|c|}{ Preterm delivery } & \multicolumn{5}{|c|}{ Birthweight $<2500$ g } \\
\hline & \multicolumn{2}{|c|}{$\begin{array}{l}\text { Continental } \\
\text { France }\end{array}$} & \multicolumn{3}{|c|}{$\begin{array}{l}\text { French West } \\
\text { Indies }\end{array}$} & \multicolumn{2}{|c|}{$\begin{array}{l}\text { Continental } \\
\text { France }\end{array}$} & \multicolumn{2}{|c|}{$\begin{array}{l}\text { French West } \\
\text { Indies }\end{array}$} & \\
\hline & No & $\%$ & No & $\%$ & & No & $\%$ & No & $\%$ & \\
\hline $\begin{array}{l}\text { All women } \\
\text { Nurses } \\
\text { Auxiliaries } \\
\text { Ancillary staff } \\
\text { Other occupations }\end{array}$ & $\begin{array}{r}427 \\
188 \\
40 \\
55 \\
144\end{array}$ & $\begin{array}{r}6 \\
7 \\
3 \\
11 \\
5 \\
\text { ns }\end{array}$ & $\begin{array}{r}160 \\
25 \\
55 \\
54 \\
26\end{array}$ & $\begin{array}{r}14 \\
12 \\
11 \\
22 \\
8 \\
\text { ns }\end{array}$ & $\begin{array}{l}\not \neq \neq \\
\text { ns } \\
\text { ns } \\
\text { ns } \\
\text { ns }\end{array}$ & $\begin{array}{r}431 \\
191 \\
39 \\
56 \\
145\end{array}$ & $\begin{array}{r}6 \\
6 \\
3 \\
14 \\
2 \\
\text { ns }\end{array}$ & $\begin{array}{r}163 \\
25 \\
56 \\
54 \\
28\end{array}$ & $\begin{array}{c}5 \\
4 \\
2 \\
7 \\
7 \\
\text { ns }\end{array}$ & $\begin{array}{l}\text { ns } \\
\text { ns } \\
\text { ns } \\
\text { ns } \\
\text { ns }\end{array}$ \\
\hline
\end{tabular}

No = total number of mothers in group

$\psi_{0}=$ per cent with the particular characteristic

ns $p>0.05 \neq \neq p<0.01$ 
Table 3 Development and outcome of pregnancy according to indicator of strenuous working conditions and occupation

\begin{tabular}{|c|c|c|c|c|c|c|c|c|}
\hline \multirow{2}{*}{$\begin{array}{l}\text { Occupation } \\
\text { and indicator } \\
\text { of working } \\
\text { conditions* }\end{array}$} & \multicolumn{2}{|c|}{$\begin{array}{l}\text { Uterine } \\
\text { contractions }\end{array}$} & \multicolumn{2}{|c|}{ Hypertension } & \multicolumn{2}{|c|}{$\begin{array}{l}\text { Preterm } \\
\text { delivery }\end{array}$} & \multicolumn{2}{|c|}{$\begin{array}{l}\text { Birthweight } \\
<2500 \mathrm{~g}\end{array}$} \\
\hline & No & $\%$ & No & $\%$ & No & $\%$ & No & $\%$ \\
\hline \multicolumn{9}{|l|}{ All women } \\
\hline 0 or 1 & 477 & 45 & 477 & 11 & 469 & 6 & 475 & 5 \\
\hline \multirow[t]{2}{*}{2 or 3} & 114 & 63 & 114 & 30 & 111 & 21 & 112 & 8 \\
\hline & & $\not \neq \neq$ & & $\neq \neq \neq$ & & $\neq \neq \neq$ & & ns \\
\hline \multicolumn{9}{|l|}{ Nurses } \\
\hline 0 or 1 & 190 & 51 & 190 & 13 & 187 & 7 & 190 & 7 \\
\hline \multirow[t]{2}{*}{2 or 3} & 25 & 72 & 25 & 32 & 25 & 8 & 25 & 4 \\
\hline & & $\neq$ & & $\neq$ & & ns & & ns \\
\hline \multicolumn{9}{|l|}{ Auxiliaries } \\
\hline 0 or 1 & 73 & 44 & 73 & 10 & 71 & 4 & 71 & 1 \\
\hline \multirow[t]{2}{*}{2 or 3} & 25 & 52 & 25 & 28 & 24 & 17 & 24 & 4 \\
\hline & & ns & & ns & & ns & & ns \\
\hline \multicolumn{9}{|l|}{ Ancillary staff } \\
\hline 0 or 1 & 63 & 51 & 63 & 8 & 62 & 6 & 63 & 8 \\
\hline \multirow{2}{*}{2 or 3} & 48 & 71 & 48 & 31 & 47 & 30 & 47 & 13 \\
\hline & & $\neq$ & & $\neq \neq \neq$ & & $\not \neq$ & & ns \\
\hline \multicolumn{9}{|l|}{$\begin{array}{l}\text { Other } \\
\text { occupations }\end{array}$} \\
\hline 0 or 1 & 151 & 37 & 151 & 11 & 149 & 4 & 151 & 3 \\
\hline 2 or 3 & 16 & 44 & 16 & 25 & 15 & 20 & 16 & 16 \\
\hline & & ns & & ns & & ns & & ns \\
\hline
\end{tabular}

No $=$ total number of mothers in group

$\Psi_{1}=$ percent with the particular characteristic

ns $p>0.05 \neq p<0.05 \neq \neq p<0.01 \neq \neq \neq p<0.001$

*Accumulation of three strenuous working conditions: carrying heavy loads. long standing position, heavy cleaning tasks. The indicator varies from 0 to 3 according to whether the occupation involves none, one, two, or all three strenuous working conditions.

outcomes such as perinatal death or congenital defects is very low, and the number of anaesthetists, laboratory and $x$-ray technicians included in the survey was too small to allow such an analysis. Such specific risks have already been noted by several authors. ${ }^{217-19}$

All women who had worked less than a trimester during pregnancy have been excluded, mainly for two reasons. Firstly, these women had been exposed to working conditions involving potential risks of adverse outcome during too short a period of time for these working conditions to be validly considered as the cause. Secondly, most of these women had stopped working very early in pregnancy for medical reasons; they thus constituted a group at high risk, independently of their work, and we have preferred to take the chance of underestimating the frequency of preterm delivery and other adverse outcomes in the studied population, rather than attribute them wrongly to working conditions.

Women who had resumed their work later than 36 weeks after delivery have also been systematically excluded from the sample: after their postnatal leave, most of them had taken a parental leave, as allowed by the French legislation. They were not a group at particularly high risk; they have been excluded
Table 4 Hospital admissions and sick leave during pregnancy according to indicator of strenuous working conditions and occupation

\begin{tabular}{|c|c|c|c|c|}
\hline \multirow{2}{*}{$\begin{array}{l}\text { Occupation and } \\
\text { indicator of working } \\
\text { conditions }\end{array}$} & \multicolumn{2}{|c|}{$\begin{array}{l}\text { Hospital } \\
\text { admission }\end{array}$} & \multicolumn{2}{|c|}{$\begin{array}{l}\text { Average number of days } \\
\text { sick leave }\end{array}$} \\
\hline & No & $\psi_{1}$ & No & No of days \\
\hline \multicolumn{5}{|l|}{ All women } \\
\hline 0 or 1 & 475 & 16 & 477 & 37 \\
\hline 2 or 3 & 114 & 35 & 114 & 50 \\
\hline & & $\not \neq \neq \neq$ & & $\neq \neq \neq \neq$ \\
\hline \multicolumn{5}{|l|}{ Nurses } \\
\hline 0 or 1 & 188 & 17 & 190 & 43 \\
\hline \multirow[t]{2}{*}{2 or 3} & 25 & 32 & 25 & 53 \\
\hline & & ns & & ns \\
\hline \multicolumn{5}{|l|}{ Auxiliaries } \\
\hline 0 or 1 & 73 & 18 & 73 & 40 \\
\hline \multirow[t]{2}{*}{2 or 3} & 25 & 28 & 23 & 43 \\
\hline & & ns & & ns \\
\hline \multicolumn{5}{|l|}{ Ancillary staff } \\
\hline 0 or 1 & 63 & 11 & 63 & 36 \\
\hline \multirow[t]{2}{*}{2 or 3} & 48 & 48 & 48 & 55 \\
\hline & & $\neq \neq \neq \neq$ & & $\neq \neq$ \\
\hline \multicolumn{5}{|l|}{ Other occupations } \\
\hline 0 or 1 & 151 & 17 & 151 & 29 \\
\hline \multirow[t]{2}{*}{2 or 3} & 16 & 19 & 16 & 40 \\
\hline & & ns & & ns \\
\hline
\end{tabular}

No = total number of mothers in group

$\psi_{1}=$ percent with the particular characteristic

ns $p>0.05 \neq \neq p<0.01 \quad \neq \neq \neq p<0.001$

Accumulation of three strenuous working conditions: carrying heavy loads long standing position, heavy cleaning tasks. The indicator varies from 0 to 8 according to whether the occupation involves none, one, two, or all three strenuous working conditions.

$\dot{r}$ Including the additional two weeks of antenatal leave in case of pathologicat pregnancy.

because of the time that elapsed between the birtlo. $\vec{\omega}$ and the interview and consequently the possible lack or of accuracy of the data collected on pregnancy and delivery.

Two of the indicators used to characterise the evolution and outcome of pregnancy, uterine contractions and preterm deliveries, need to be discussed in view of the retrospective nature of the collected data. Regular and/or painful uterine contractions between the fourth and seventh months of pregnancy were considered as a signal of danger of preterm interruption of the pregnancy. In $85 \%$ of the cases some treatment was prescribed: interruption of work, bed rest, drug, or hospitalisation; in $79 \%$ of all cases, these contractions recurred. Preterm delivery was defined according to the duration of gestation as declared by the women, rather than by the date of their last menstrual period. The reasons motivating this choice have been described elsewhere. ${ }^{13}$ They were based principally on the fact that $11 \%$ of the women did not know the date of the last menstruation, while only $2 \%$ of the women were unaware of the duration of gestation. Moreover, this declared duration of gestation correlated more closely with the condition of the infant (weight, neonatal reanimation, admission to a special care 
unit) than did the duration of gestation determined from the date of the last menstrual period. Finally, the relationship between low birthweight and working conditions followed the same trend as for preterm deliveries.

In the relationship between working conditions and the development and outcome of pregnancy, one must distinguish the social aspect from the more physical impact of arduous working conditions. The women who are employed in socially underprivileged occupations must more frequently carry out tasks that are taxing from the physical or nervous point of view, thus accumulating several factors that place the outcome of the pregnancy at risk. ${ }^{40}$ In order better to determine the influence of working conditions, we studied a specific professional group, thus limiting to some extent social heterogeneity. All the women belonged to the same institution and thus enjoyed the same social advantages, for example, the reduction of one hour in the length of the workday, beginning with the third month of pregnancy. Furthermore, we verified that the difference between occupations in the development and outcome of the pregnancy was not fully attributable to the predominant social characteristics of each occupation. Finally, for each occupation, working conditions were analysed.

Exposure to three specific working conditions: heavy cleaning involving the washing of floors and windows, carrying heavy loads (other than lifting patients), long periods of standing, and, above all, their accumulation was linked to higher frequencies of uterine contractions, high blood pressure, and preterm delivery. Carrying heavy loads and long periods of standing had already been pointed out as factors of preterm risk. ${ }^{4}=21$ The accumulation of these arduous working conditions partly explained the higher frequency of pathological conditions among ancillary staff members. When the women were exposed to only one of the three arduous working conditions at most, the preterm rate was about the same for all occupations. When they were exposed to two, or to the three, stenuous working conditions, the preterm delivery rate was higher among ancillary staff. This higher level of preterm deliveries might be explained by a longer duration of exposure to these working conditions among the ancillary staff than among nurses or auxiliaries. One can presume, for example, that they spend more time doing heavy cleaning, carrying heavy loads, and remaining in a standing position than the nurses or auxiliaries who, nonetheless, can also be exposed to the same accumulation of arduous working conditions. The survey data did not permit us to test this hypothesis.

According to the survey data, modifying these working conditions and, especially, their accumulation during pregnancy would necessitate changes in the activities of $20 \%$ of all pregnant women among the hospital personnel and, most particularly, in the activities of $40 \%$ of the ancillary staff.

Studies should be conducted to evaluate the advantages of changes in the distribution of duties during pregnancy. But, in the light of present epidemiological and ergonomic knowledge of hospital work, ${ }^{811}$ there is a real need to evaluate more general modifications in the organisation of the work place to reduce the physical and mental load. Beyond the improvement in health that such measures could provide for pregnant women, as well as for the personnel in general, one could expect a diminution of the frequency of hospitalisation and of the duration of sick leave. Such sick leave, which lasts two weeks longer, on average, for women exposed to arduous working conditions, appears to be a result of the occurrence of pathology, but also a preventive measure in the face of excessive fatigue or working conditions known to be harmful to pregnancy. Improvements in working conditions may present real difficulties in the organisation of the hospital's services; these difficulties should be evaluated and compared to those provoked by sick leave whose frequency and duration could be reduced by the improvements.

This study was conducted by "Unité 149, INSERM" (Dr C Rumeau-Rouquette) with the collaboration of the "Service de Médecine du Travail des Personnels de l'Assistance Publique" (Dr J Durgeat, Dr J P Boutron) and especially the hospital staff occupational health practitioners of the hospitals surveyed: N Bonnet, F Fonchain, M Giorgi, Y Glomaud, J M Leroux, L Mousel, A Pelletier, S Quesemand, and D Schaller.

We thank M Corre for secretarial assistance.

The research was supported in part by a grant from the Délégation Générale à la Recherche Scientifique et Technique (RESACT 79-7-IIII).

\section{References}

${ }^{1}$ Chamberlain G, Garcia J. Pregnant women at work. Lancet 1983; i: 228-30.

${ }^{2}$ Barlow SM, Sullivan FM. Reproductive hazards of industrial chemicals. London: Academic Press, 1982.

${ }^{3}$ Whorton MD. Adverse reproductive outcomes: The occupational health issue of the 1980 's. $A J P H$ 1983; 73: 15-6.

${ }^{4}$ Mamelle N, Laumon B, Lazar P. Prematurity and occupational activity during pregnancy. Am J Epidemiol 1984; 3: 309-22.

${ }^{5}$ Saurel-Cubizolles MJ, Kaminski M, Rumeau-Rouquette C. Activité professionnelle des femmes enceintes, surveillance prénatale et issue de la grossesse. J Gyn Obst Biol Repr 1982; 11: 959-67. 
${ }^{6}$ Saurel-Cubizolles MJ, Kaminski M. Pregnant women at work. Lancet 1983; i: 475.

${ }^{7}$ Murphy JF, Dauncey M, Newcombe R, Garcia J, Elbourne D. Employment in pregnancy: Prevalence, maternal characteristics, and perinatal outcome. Lancet 1984; i: 1163-5.

${ }^{8}$ Estryn M, Kaminski M, Franc M, et al. Grossesse et conditions de travail en milieu hospitalier. Rev Franc Gynec 1978; 73: 625-31.

${ }^{9}$ Ministère des Affaires Sociales et de la Solidarité Nationale. Annuaire des statistiques sanitaires et sociales 1982-83. Paris: La Documentation française, 1983.

${ }^{10}$ INSEE. Données sociales, édition 1981. Paris: 1981.

${ }^{11}$ Pottier M, Estryn-Behar M. L'ergonomie en milieu hospitalier. Le travail humain 1980; 43: 121-53.

${ }^{12}$ Estryn-Behar M, Fonchain F, Becker JC. Analyse de problèmes médicaux liés au travail dans une équipe de ménage. Arch Mal Prof 1983; 44: 518-20.

${ }^{13}$ Kaminski M, Saurel-Cubizolles MJ, Estryn-Behar M. Déroulement et issue de la grossesse des femmes travaillant en milieu hospitalier, selon la fonction exercée et les conditions de travail. Rapport DGRST, in preparation.

${ }^{14}$ Butler NR, Alberman EA. Perinatal problems. Edinburgh: Livingstone, 1969.
${ }^{15}$ Rumeau-Rouquette $\mathrm{C}$ et Unité 149. Naitre en France. INSERM, Paris, 1979.

${ }^{16}$ Kaminski M, Blondel B. Déroulement et issue de la grossesse chez les femmes immigrées, approche médico-sociale. Prévenir 1983; 7: 33-43.

${ }^{17}$ Holmberg PC. Central nervous system defects in children born to mothers exposed to organic solvents during pregnancy. Lancet 1979; i: 177-9.

${ }^{18}$ Pharaoh POD, Alberman E, Coyle P. Outcome of pregnancy among women in anaesthetic practice. Lancet 1977; i: 34-6.

${ }^{19}$ Ericson A, Kallen B. Survey of infants born in 1973 or 1975 to Swedish women working in operating rooms during their pregnancies. Anesth Analg 1979; 58: 302-5.

${ }^{20}$ Saurel-Cubizolles MJ. Activité professionnelle des femmes enceintes, comportement médical et issue de la grossesse. Approche socio-historique et épidémiologique. Thèse de 3ème cycle, Université Paris I, Paris, 1982.

${ }^{21}$ Papiernik E. Fatigue et résultat de la grossesse. In: Monaco 2: vers une grossesse sans risque. Courbevoie: Nestlé Guigoz, 1973; 214-20. 